\title{
METHOD OF DIAGNOSIS AND TREATMENT OF PROFUSIONAL BLEEDING FROM STENOSING POSTBULBAR ULCERS OF THE DUODENUM
}

\author{
Volodymyr Mamchych \\ Department of Surgery and Proctology $y^{l}$ \\ mamchichvi@ukr.net \\ Sergiy Vereshchagin \\ Department of Surgery and Proctologyl \\ doctor-sv@i.ua \\ Volodymyr Maksymchuk \\ KNP «Chornobayev Multidisciplinary Hospital of Chornobayev District Council» \\ 221 Tsentralna str., Chornobay, Cherkasy region, Ukraine, 19901 \\ maksimchukvd@ukr.net \\ Dmytro Maksymchuk \\ Department of Surgery and Proctology $y^{l}$ \\ mdv128@ukr.net \\ ${ }^{1}$ Shupyk National Medical Academy of Postgraduate Education \\ 9 Dorohozhytska str., Kyiv, Ukraine, 04112 \\ Kyiv Regional Clinical Hospital \\ 1 Baggovutivska str., Kyiv, Ukraine, 04107
}

\begin{abstract}
The aim. To evaluate the effectiveness of X-ray interventions in arosive bleeding in patients with complicated duodenal ulcer.

Materials and methods. X-ray endovascular interventions were used in 8 patients who developed arosive bleeding as a complication of duodenal ulcer. All patients with signs of gastrointestinal bleeding were examined according to clinical protocols. Hemodynamically stable patients underwent X-ray endovascular interventions.

Results and discussion. In the near future, bleeding stopped in all $8(100 \%, \mathrm{OR}-0.04[0.005-0.29], p=0.03)$ patients. On day 2 , two patients who underwent embolization of their own hepatic artery had a recurrence of bleeding $(0.56[0.065-4.76], p=0.29)$. Repeated angiography and embolization attempts were ineffective, and both patients died. In patients who underwent gastroduodenal and pancreatouodenal artery embolization, bleeding did not resume. Thus, we obtained good results as 6 out of 8 patients recovered $(75 \%)$, despite the severity of their condition and a disappointing prognosis (OR-9.0 [1.0-46.7], $p<0.05$ ).

Conclusions. Adherence to the tactics mentioned above in the treatment of bleeding in duodenal ulcer was highly effective, especially in superselective embolization with the detection of bleeding gel. If the presence of arosive bleeding is confirmed, emergency surgical treatment with suturing of the damaged vessel is shown in hemodynamically unstable patients, and endovascular intervention is possible in hemodynamically stable patients. Further studies are needed to determine the criteria for a high risk of arosive bleeding developing in patients with complicated duodenal ulcer as well as to prevent its occurrence through the use of $\mathrm{X}$-ray endovascular interventions.
\end{abstract}

Keywords: Duodenal ulcer, X-ray endovascular interventions, arosive bleeding.

DOI: $10.21303 / 2504-5679.2021 .001730$

\section{Introduction}

The prevalence of duodenal ulcer among the general population is 5-10\%; the disease is verified with a frequency of $0.1-0.3 \%$ per year. The disease is more common in men, the ratio of men to women ranges from 2:1 to $10: 1[1,2]$.

Complications of peptic ulcer disease, such as perforation and bleeding, have a significant economic impact. The total cost of peptic ulcer treatment in the United States, which includes both direct costs and loss of productivity, is estimated at $\$ 5.65$ billion per year [3]. Acute bleeding from the 
upper gastrointestinal tract accounts for $>400,000$ hospitalizations per year in the United States [4]. According to other statistical studies, in the European Union, the cost of bleeding, perforation or a combination of them per person is 12,000, 19,000 and 26,000 euros per patient respectively [5].

Bleeding from the upper gastrointestinal tract is the most common and unfavorable complication of duodenal ulcer, which is $31 \%-67 \%$ of all cases of gastrointestinal bleeding $[1,6]$. This condition, which requires immediate medical intervention, is accompanied by a high mortality rate (up to $10 \%$ ) [7]. However, according to other studies, over the past few decades, the mortality rate, depending on the quality of care, has decreased to 3.5-7.4 \% [8].

Helicobacter pylori infection, non-steroidal anti-inflammatory drugs and aspirin are considered to be the main risk factors for gastrointestinal bleeding [7, 9]. The risk of mortality, according to the recommendations of the American Society of Anesthesiologists, is associated with the following features: hemoglobin $<70.0 \mathrm{~g} / 1$, age $>80$ years, renal failure, bleeding due to failed endoscopic intervention. Moreover, the failure rate during medical endoscopy immediately after the intervention reaches $10 \%$, within 24-72 hours - $20 \%[8,10]$.

A number of methods can be used to stop and prevent further bleeding, including conservative therapy, endoscopic, injection (adrenaline), thermoablative (coagulation probes) and mechanical methods [11].

Thermal and mechanical methods of hemostasis are the most effective [12]. In addition, dual therapy, for example, mechanical hemostasis with endoclips, remains the optimal endoscopic therapy, according to the latest recommendations [13]. Despite the fact that a variety of endoscopic clips are available today, there is no evidence of a clear advantage of any type [14].

The next method, which is used in case of unsuccessful endoscopic hemostasis, is open surgery; however, the mortality rate in this case can reach $40 \%$. Trans-catheter arterial embolization (TAE) may be suggested as an alternative to surgery in groups of patients with recurrent bleeding, high-risk groups, and if endoscopic hemostasis has not been successful [15]. The effectiveness of endoscopic ultrasonography under the control of angiotherapy has been considered in a number of small studies. Angiotherapy is effective in patients with lesions in which insufficient efficacy has been obtained with typical endoscopic methods [16].

The number of patients undergoing surgery for bleeding has decreased sharply with the introduction into widespread clinical practice in the treatment of bleeding in peptic ulcer of the stomach and duodenum, endoscopic methods of hemostasis, proton pump inhibitors and antibiotics. However, despite significant changes in the treatment tactics of gastrointestinal bleeding of ulcerative origin in the last 50 years, mortality has not changed significantly (6-13\%) [17].

Endoscopy does not reveal the source in approximately $20 \%$ of cases of bleeding from the upper digestive tract. The most common is bleeding from an ulcer or from varicose veins of the esophagus and stomach [18].

Thus, the choice of diagnosis and the optimal method of treatment for bleeding duodenal ulcers remains an open problem of emergency surgery. Factors such as endoscopist's skill, hemodynamic instability, poor sedation, poor visualization, and difficult reach can affect the level of complications. In addition, factors that may affect the failure of endoscopic hemostasis include: large ulcers ( $2 \mathrm{~cm}$ in size), located in the postbulbar duodenum or small curvature of the stomach, active bleeding, the presence of comorbidities. All these factors require careful analysis and additional study in order to select the best method of surgical treatment.

The aim of the research was to evaluate the effectiveness of X-ray interventions in arosive bleeding in patients with complicated duodenal ulcer.

\section{Materials and methods of the research}

The results of surgical treatment of complicated duodenal ulcer are presented according to the materials of the surgical department of the Kyiv Regional Clinical Hospital (base of the Department of Surgery and Proctology of the National Medical Academy of Postgraduate Education named after P. L. Shupyk) published in 2018-2020.

X-ray endovascular intervention was used in the treatment of 8 patients with complicated duodenal ulcer who developed arosive bleeding. There were 6 men and 2 women. The mean age 
of patients was 54.2 \pm 18.8 years (age range 34-74 years). Patients were taken to hospital within 2 hours to 1 day with signs of gastrointestinal bleeding. All patients underwent standard laboratory methods (general clinical, biochemical, coagulation tests) and used instrumental diagnostic methods: FGDS, ultrasound of the abdominal cavity, spiral computed tomography (CT) with contrast enhancement (ultravist intravenous and triombrast $76 \%$ orally).

For statistical analysis of the obtained results a package of general purpose data processing programs Statistica for Windows version 10.0 (Stat Soft inc., USA) was used. Evaluation of treatment efficacy was performed taking into account the odds ratio (OR) of drugs, with the calculation of confidence intervals and the criterion of reliability and OR. At $p<0.05$ discrepancies were considered statistically significant.

All patients received a full range of infusion and conservative therapy in the intensive care unit. In $6(75 \pm 4.5 \%)$ patients bleeding was detected by blood per rectum. In $2(25 \pm 3.8 \%)$ patients bleeding detected by nasogastric tube (Fig. 1) was accompanied by signs of gastrointestinal bleeding. In $2(25 \pm 1.7 \%)$ patients bleeding occurred on the 2 nd day after hemostatic therapy, in 6 patients $(75 \pm 6.1 \%)$ - within the next 5-6 days. In $2(25 \pm 4.1 \%)$ patients the bleeding was diffuse.

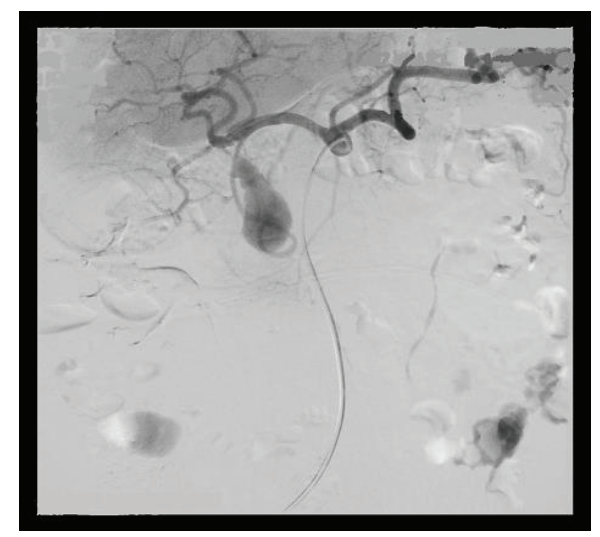

Fig. 1 Superselective catheterization of the pancreatic-duodenal artery. Extravasation of contrast into the lumen of the duodenum

During endovascular intervention, arterial access was performed from the right femoral artery according to Salinger under local anesthesia with $0.5 \%$ solution of novocaine. Preliminary diagnostic angiography was performed with the inclusion of selective arteriography of the abdominal trunk and superior mesenteric artery with the obligatory obtaining of arterial, parenchymal and venous phases, followed by endovascular embolization of bleeding arteries, by introduction the embolizing spirals through arteries. The embolizing spirals are injected into both the afferent and excretory part of the vessel, and if possible also into the cavity of the false aneurysm, which is the cause of bleeding.

In addition, embolization of the bleeding artery is performed with a hemostatic sponge with calibrated synthetic emboli, which have a particle size of 1000-2000 microns.

Embolization of a false aneurysm is performed with a microcatheter, through which microcoils having a system of controlled electrical or mechanical separation from the catheter are superselectively inserted into the cavity of the aneurysm and into the artery supplying it with precision. Such embolization is performed in case of inaccessibility of the lesion area with standard angiographic catheters (usually microcoils are used in interventional neuroradiology).

This method allows both the diagnosis of profuse duodenal hemorrhage from stenotic postbulbar ulcers and their subsequent controlled treatment by endovascular embolization while maintaining organ function without recurrence of bleeding and achieving a rapid and reliable hemostatic effect [19].

The method is implemented as follows.

First, a preliminary diagnostic angiography is performed, which includes selective arteriography of the abdominal trunk and superior mesenteric artery, with the obligatory obtaining of the arterial, parenchymal and venous phases. 
The main sources of blood supply in this anatomical area are usually a. transcreaticoduodenalis superior (from the pool of a. gastroduodenalis, departing from a. hepatis communis) and a. pancreaticoduodenalis inferior (from the pool of a. mesenterica superior), which form an arterial arch and are interconnected by a network of anastomoses.

Characteristic angiographic symptoms of bleeding such as false aneurysms or temporary occlusions (thrombosis) of bleeding arteries are found in the projection of the hepatopancreatoduodenal area. In some cases, a symptom of contrast extravasation outside the bleeding artery (found in $10-20 \%$ of cases with particularly severe profuse bleeding with a blood flow rate of more than 0.5 cubic $\mathrm{cm} / \mathrm{min}$.) was detected [20].

After diagnosing the symptoms and establishing the cause of bleeding in patients, endovascular embolization of bleeding arteries is performed (if technically possible, their superselective catheterization).

Embolization is performed by inserting metal coils of the Gianturco type with dimensions corresponding to the caliber of the occluded artery through a superselectively installed conventional or hydrophilic angiographic catheter of the appropriate configuration (usually type «Sobra Visceral, «Selective Virseral», «Multipurpose»). These spirals are currently produced by several manufacturers and can have different configurations - cylindrical, spindle-shaped, hourglass type, spherical (3D), conical (type «Tornado»). Embolizing spirals are inserted into both the leading and diverting part of the vessel (to prevent recurrence of bleeding due to the restoration of retrograde blood flow to the area of vascular damage), and if possible the spiral is also inserted into the cavity of the false aneurysm to ensure its complete exclusion from blood flow. In some cases, in addition to trunk embolization of arteries with spirals, additional embolization with a hemostatic sponge and calibrated synthetic emboli, which have a particle size of 1000-2000 $\mu \mathrm{m}$, is performed, which allows to achieve a faster and more reliable hemostatic effect. The use of smaller particles is undesirable due to the risk of ischemic complications in the area of embolization.

If, in a patient with a false branch aneurysm a. mesenterica superior to reach the aneurysm cavity with a conventional angiographic catheter is technically impossible, and semi-selective embolization can lead to intestinal necrosis due to emboli in the adjacent branches of the target artery, embolization of the defective aneurysm is performed by a microcatheter in which precision microspirals are introduced, which have a system of electrically or mechanically controlled separation from the catheter (usually they are used in interventional neuroradiology). After the procedure, the catheter was removed from the arterial bed, a compression bandage was applied to the puncture site, and patients were adhered to a strict bed rest during the day, and received conservative therapy in the intensive care unit.

Example I. Patient /medical history N 27025/477/313/ was admitted to the surgical department of CE KRC «Kyiv Regional Clinical Hospital» with a diagnosis of duodenal ulcer, subcompensated pyloroduodenal stenosis, ulcer penetration, acute bleeding. Fibrogastroscopy revealed subcompensated pyloroduodenal stenosis, postbulbar ulcer, with a bleeding vessel. Due to the stable condition of the patient, the proposed method was used. Postoperative period was without complications. On the 10th day after surgery, the patient was discharged from the hospital in satisfactory condition.

\section{Results}

After stabilization, patients underwent endovascular intervention to prevent subsequent episodes of bleeding. Acute bleeding from the gastroduodenal artery was diagnosed in $4(50 \pm 4.51 \%)$ patients, acute bleeding from the pancreato-duodenal-intestinal artery was diagnosed in $2(25 \pm 3.8 \%)$ patients and the source of bleeding is not detected in $2(25 \pm 4.1) \%)$ patients. Respectively, $4(50 \pm 6.71 \%)$ patients underwent gastroduodenal artery embolization (Fig. 2), $2(25 \pm 3.95 \%)$ patients underwent pancreatic - intestinal artery embolization and $2(25 \pm 2,91 \%)$ of patients - embolization of the initial section of the common hepatic artery before the discharge of the pancreatic -duodenal-intestine artery.

In the near future, bleeding stopped in all $8(100 \%$, OR-0.04 [0.005-0.29], $p=0.03)$ patients. On day 2, two (25\%) patients who underwent embolization of the common hepatic artery 
had a recurrence of bleeding $(0.56$ [0.065-4.76], $p=0.29)$. Repeated angiography and embolization attempts were ineffective. Laparotomy revealed that the bleeding was diffuse in nature, the source could not be localized, and those patients performed stitching of the most dubious areas of the duodenal mucosa. However, both patients died soon. In patients who underwent gastroduodenal artery embolization, bleeding did not resume. Thus, we obtained good results -6 patients $(75 \%)$ survived out of 8 , despite the severity of the condition and the disappointing prognosis (OR-9.0 [1.0-46.7], $p<0.05)$. The selective embolization of the gastroduodenal artery and superselective pancreaticduodenal artery was the most effective, and there was no recurrence of bleeding at all.

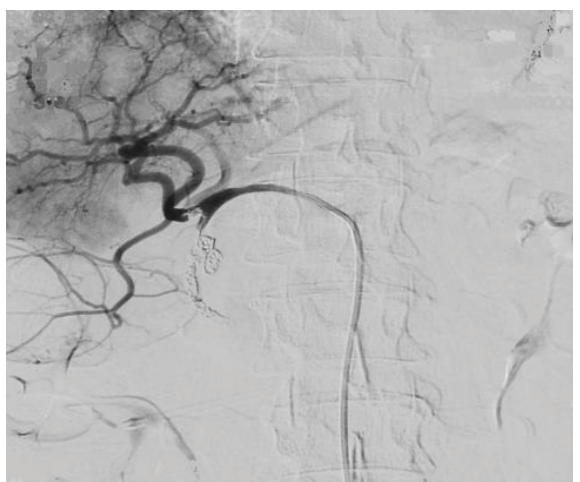

Fig. 2. Endovascular embolization of a bleeding artery by introduction of embolizing metal spirals through a superselectively established angiographic catheter

Regarding the occurrence of ischemia of organs distal to embolization in our practice, we did not observe such complications, except for the appearance of hematomas in the femoral artery.

\section{Discussion of research results}

According to the literature, the source of bleeding is usually gastroduodenal, gastric source - duodenal, intestinal, left gastric, common or own hepatic artery, as well as the portal hepatic vein [21]. Bleeding due to a violation of the artery integrity may be in the duodenum, pancreatic duct, intra - or retroperitoneally. The first and second variants of bleeding are manifested in the form of a clinical picture of gastrointestinal bleeding, the third and fourth - the presence of blood in the drainage systems fixed earlier [22].

The literature provides various data on the development of recurrence of bleeding after embolization. The recurrence rate of bleeding in a study by F.Boudghene et al. was $37 \%$ [23]. In contrast, H. Sethi and co-authors [24] did not observe any episodes of re-bleeding, all patients recovered. We found signs of re-bleeding in only $2(25 \%)$ patients who later died.

Open surgical treatment of arosive ulcerogenic (duodenal) bleeding is indicated in case of hemodynamic instability of the patient, unavailability of endovascular service or failure of attempt of X-ray vascular treatment. Surgical treatment for this type of bleeding is to suture the damaged vessel. H. Hyare and co-authors reported that the overall mortality in open surgical treatment of arosive pancreatogenic bleeding is 23 that equal $30 \%$, which is much higher than the corresponding figure in the endovascular approach [25]. We believe that this statement is quite identical to duodenal bleeding. However, it is important to note that these authors performed laparotomy in hemodynamically unstable patients who already had bleeding, in contrast to the interventional approach in hemodynamically stable patients who are at high risk of bleeding according to instrumental methods, for example, did not consider the possibility of X-ray endovascular interventions to prevent bleeding.

\section{Conclusions}

1. If signs of gastrointestinal bleeding are detected in patients with complicated duodenal ulcer, it is recommended to perform fibrogastrodoudenoscopy, and perform CT angiography or direct selective angiography of the vessels of the abdominal cavity in order to exclude such 
a threatening complication of peritoneal arthritis as arosive bleeding from the peripancreatic (gastroduodenal) arteries.

2. If the presence of arosive bleeding is confirmed, emergency surgical treatment with suturing of the damaged vessel is shown in hemodynamically unstable patients, and endovascular intervention is possible in hemodynamically stable patients.

3. Further studies are needed to determine the criteria for a high risk of developing arosive bleeding in patients with complicated duodenal ulcer and to prevent its occurrence through the use of X-ray endovascular interventions.

\section{Conflict of interests}

The authors declare that they have no conflicts of interest.

\section{References}

[1] Tarasconi, A., Coccolini, F., Biffl, W. L., Tomasoni, M., Ansaloni, L., Picetti, E. et. al. (2020). Perforated and bleeding peptic ulcer: WSES guidelines. World Journal of Emergency Surgery, 15 (1). doi: http://doi.org/10.1186/s13017-019-0283-9

[2] Garber, A., Jang, S. (2016). Novel Therapeutic Strategies in the Management of Non-Variceal Upper Gastrointestinal Bleeding. Clinical Endoscopy, 49 (5), 421-424. doi: http://doi.org/10.5946/ce.2016.110

[3] Gurusamy, K. S., Pallari, E. (2016). Medical versus surgical treatment for refractory or recurrent peptic ulcer. Cochrane Database of Systematic Reviews, 3. doi: http://doi.org/10.1002/14651858.cd011523.pub2

[4] Ouali, S. E., Barkun, A. N., Martel, M., Maggio, D. (2014). Timing of Rebleeding in High-Risk Peptic Ulcer Bleeding after Successful Hemostasis: A Systematic Review. Canadian Journal of Gastroenterology and Hepatology, 28 (10), $543-548$. doi: http://doi.org/10.1155/2014/324967

[5] Narayanan, M., Reddy, K. M., Marsicano, E. (2018). Peptic Ulcer Disease and Helicobacter pylori infection. Missouri Medicine, 115 (3), 219-224.

[6] Tarasconi, A., Baiocchi, G. L., Pattonieri, V., Perrone, G., Abongwa, H. K., Molfino, S. et. al. (2019). Transcatheter arterial embolization versus surgery for refractory non-variceal upper gastrointestinal bleeding: a meta-analysis. World Journal of Emergency Surgery, 14 (1). doi: http://doi.org/10.1186/s13017-019-0223-8

[7] Szura, M., Pasternak, A. (2015). Upper non-variceal gastrointestinal bleeding - review the effectiveness of endoscopic hemostasis methods. World Journal of Gastrointestinal Endoscopy, 7 (13), 1088-1095. doi: http://doi.org/10.4253/ wjge.v7.i13.1088

[8] Kim, K. B., Yoon, S. M., Youn, S. J. (2014). Endoscopy for Nonvariceal Upper Gastrointestinal Bleeding. Clinical Endoscopy, 47 (4), 315-319. doi: http://doi.org/10.5946/ce.2014.47.4.315

[9] Jang, J.-Y. (2016). Recent Developments in the Endoscopic Treatment of Patients with Peptic Ulcer Bleeding. Clinical Endoscopy, 49 (5), 417-420. doi: http://doi.org/10.5946/ce.2016.135

[10] Barkun, A., Al Dhahab, H., McNabb-Baltar, J., Al-Taweel, T. (2013). State-of-the-art management of acute bleeding peptic ulcer disease. Saudi Journal of Gastroenterology, 19 (5), 195-204. doi: http://doi.org/10.4103/1319-3767.118116

[11] Jafar, W., Jafar, A. J. N., Sharma, A. (2014). Upper gastrointestinal haemorrhage: an update. Frontline Gastroenterology, 7 (1), 32-40. doi: http://doi.org/10.1136/flgastro-2014-100492

[12] Weber, D. G., Bendinelli, C., Balogh, Z. J. (2013). Damage control surgery for abdominal emergencies. British Journal of Surgery, 101 (1), e109-e118. doi: http://doi.org/10.1002/bjs.9360

[13] Malfertheiner, P., Schulz, C. (2020). Peptic Ulcer: Chapter Closed? Digestive Diseases, 38 (Suppl. 2), 112-116. doi: http://doi.org/ $10.1159 / 000505367$

[14] Beales, I. (2017). Recent advances in the management of peptic ulcer bleeding. F1000Research, 6, 1763. doi: http://doi.org/ 10.12688/f1000research.11286.1

[15] Kyaw, M., Tse, Y., Ang, D., Ang, T., Lau, J. (2014). Embolization versus surgery for peptic ulcer bleeding after failed endoscopic hemostasis: a meta-analysis. Endoscopy International Open, 2 (1), E6-E14. doi: http://doi.org/10.1055/s-0034-1365235

[16] Craenen, E. M. E., Hofker, H. S., Peters, F. T. M., Kater, G. M., Glatman, K. R., Zijlstra, J. G. (2013). An upper gastrointestinal ulcer still bleeding after endoscopy: what comes next? Netherlands Journal of Medicine, 71 (7), 355-358.

[17] Holster, I. L., Kuipers, E. J. (2012). Management of acute nonvariceal upper gastrointestinal bleeding: Current policies and future perspectives. World Journal of Gastroenterology, 18 (11), 1202-1207. doi: http://doi.org/10.3748/wjg.v18.i11.1202

[18] Cerqueira, R. M., Andrade, L., Correia, M. R., Fernandes, C. D., Manso, M. C. (2012). Risk factors for in-hospital mortality in cirrhotic patients with oesophageal variceal bleeding. European Journal of Gastroenterology \& Hepatology, 24 (5), $551-557$. doi: http://doi.org/10.1097/meg.0b013e3283510448 
[19] Mamchich, V. I., Vereshhagin, S. V., Maksimchuk, D. V., Maksimchuk, V. D., Chaika, M. A. (2020). Pat. No. 143527 UA. Sposib diagnostiki ta likuvannya profuznikh krovotech iz stenozuyuchikh postbulbarnikh virazok. MPK: A61B 8/12, A61B 17/00. No. u202002723. declareted: 05.05.2020; published: 27.07.2020, Bul. No. 14.

[20] Mamchich, V. I., Maksymchuk, V. D., Maksymchuk, D. V. (2020). Classification of gastroduodenal bleeding by the strength of the bleeding jet. Actual problems of transport medicine, 3 (61), 71-78. doi: http://dx.doi.org/10.5281/zenodo.4081787

[21] Flati, G., Salvatori, F., Porowska, B., Talarico, C., Fiati, D., Proposito, D. et. al. (1995). Severe hemorrhagic in pancreatitis. Annali Italiani di Chirurgia, 66 (2), 233-237.

[22] Barge, J. U., Lopera, J. E. (2012). Vascular Complications of Pancreatitis: Role of Interventional Therapy. Korean Journal of Radiology, 13 (Suppl 1), S45-S55. doi: http://doi.org/10.3348/kjr.2012.13.s1.s45

[23] Boudghène, F., L'Herminé, C., Bigot, J.-M. (1993). Arterial Complications of Pancreatitis: Diagnostic and Therapeutic Aspects in 104 Cases. Journal of Vascular and Interventional Radiology, 4 (4), 551-558. doi: http://doi.org/10.1016/ s1051-0443(93)71920-x

[24] Sethi, H., Peddu, P., Prachalias, A., Kane, P., Karani, J., Rela, M., Heaton, N. (2010). Selective embolization for bleeding visceral arteru pseudoaneurysms in patients with pancreatitis. Hepatobiliary \& Pancreatic Diseases International, 6, 634-638.

[25] Hyare, H., Desigan, S., Brookes, J. A., Guiney, M. J., Lees, W. R. (2007). Endovascular Management of Major Arterial Hemorrhage as a Complication of Inflammatory Pancreatic Disease. Journal of Vascular and Interventional Radiology, 18 (5), 591-596. doi: http://doi.org/10.1016/j.jvir.2007.02.035

How to cite: Mamchych, V., Vereshchagin, S., Maksymchuk, V., Maksymchuk, D. (2021). Method of diagnosis and treatment of profusional bleeding from stenosing postbulbar ulcers of the duodenum. EUREKA: Health Sciences, 2, 37-43. doi: http://doi.org/ 10.21303/2504-5679.2021.001730 